\title{
Complex Problem Solving: The European Perspective-10 Years After
}

\author{
Joachim Funke \\ University of Heidelberg, Germany
}

Peter A. Frensch

Humboldt University, Berlin, Germany

Twelve years have passed since the publication of Complex Problem Solving: The European Perspective (Frensch \& Funke, 1995a). In the volume, most of the prominent European researchers in the area of complex problem solving (CPS) summarized the-then current-state of the field in this relatively young and exciting area of study. As many readers know, CPS is a term that was introduced about 30 years ago in Germany by Dietrich Dörner (1975). Komplexes Problemlösen (which is the original German term) established not only a new type of problem to be studied, a type that differed from "simple" problem solving in terms of complexity, temporal dynamics, and other attributes, but also a new method, namely, the use of computer-simulated microworlds.

Since the publication of Complex Problem Solving: The European Perspective (Frensch \& Funke, 1995a), the young field's most pressing questions and preferred answers have changed. In this chapter, we focus on some of the issues that have been at the center of attention in the CPS literature during the past 12 years (see also Funke, 1999, 2006). The chapter is divided into four parts. In the first part, we briefly redescribe the historic roots of modern research on CPS and establish a working definition of the concept. In 
the second part, we discuss one specific issue that has been of interest in the CPS community lately, namely, the question to what extent, if at all, CPS performance might be related to intelligence. We discuss some of the older, and much of the most recent, research that has been concerned with exploring the link between intelligence and CPS. In doing so, we differentiate between explicit and implicit CPS. In the third part, we focus on the question to what extent, if at all, CPS can be empirically distinguished from "simple" problem solving, and if there are domain specific or domain general principles at work. In the final part of the chapter, we present and discuss 10 myths about CPS that we believe very much hampers scientific progress in the area at the present time.

\section{THE EUROPEAN PERSPECTIVE}

\section{ON COMPLEX PROBLEM SOLVING}

As pointed out by Frensch and Funke (1995b), researchers in the area of human problem solving have often been quite inconsistent in their use of terms such as problem, problem solving, and intelligence. Although perhaps understandable, different uses of the same term seriously undermine scientific progress. Because the definition of a term affects the choice of experimental tasks and methods, and thus, ultimately affects the conclusions to be drawn (Frensch \& Funke, 1995b), we make an attempt in this section to delineate what exactly we mean when we talk about "problems" in general and "complex problems" in particular. First, however, we give a brief historical overview of complex problem-solving research.

\section{Simple and Complex Problems}

Beginning with the early experimental work of the Gestaltists in Germany (e.g., Duncker, 1935), and continuing through the 1960s and early 1970s, research on problem solving was typically conducted with relatively simple laboratory tasks (e.g., Duncker's "X-ray” problem, 1935; Ewert \& Lambert's "disk" problem, 1932, later known as "Tower of Hanoi") that were novel to research participants (e.g., Mayer, 1992). Simple novel tasks were used for a variety of reasons: They had clearly defined optimal solutions, they were solvable within a relatively short time frame, research participants' problem-solving steps could be traced, and so on. The underlying assumption was, of course, that simple tasks, such as the "Tower of Hanoi," capture the main properties of "real" problems, and that the cognitive processes underlying participants' solution attempts on simple problems were representative of the processes engaged in when solving "real" problems. Thus, simple problems were used for reasons of convenience and generalizations to more complex problems were thought possible. Perhaps the best known and most impressive example of this line of research is the work by Newell and Simon (1972).

However, beginning in the 1970s, researchers became increasingly convinced that empirical findings and theoretical concepts derived from simple laboratory tasks were not easily generalizable to more complex, real-life problems. Even worse, it appeared that the processes underlying CPS in different domains were different from each other (Sternberg, 1995). These realizations have led to rather different responses in North America and Europe.

In North America, initiated by the work of Herbert Simon on learning by doing in semantically rich domains (e.g., Anzai \& Simon, 1979; Bhaskar \& Simon, 1977), researchers began to investigate problem solving separately Simon, 1977), researchers began to investigate (e.g., physics, writing, chess playin different natural knowledge domains (e.g., physics, writing, chess playing), thus relinquishing on their solving (e.g., Sternberg \& Frensch, 1991). Instead, researchers frequently focused on the development of problem solving within a certain frequertise (e.g., Anderson, Boyle, \& Reiser, 1985. Chase \& Simon, 1973; Chi, Feltovich, \& Glaser, 1981). Areas Rerth America include such diverse fields as reading, writing, calculation, political decision making managerial problem solving, lawyers' reasoning, mechanical problem solving, problem solving in electronics, computer skills, game playing, and even personal problem solving.

In Europe, two main approaches have surfaced, one initiated by Donald Broadbent (1977; see Berry \& Broadbent, 1995) in Great Britain and the other one started by Dietrich Dörner (1975, 1980; see also Dörner \& Wearing, 1995) in Germany. The two approaches have in common an emphasis on relatively complex, semantically rich, computerized laboratory tasks on relatively complex, semantically rich, computerized laboratory task that are constructed to be similar to real-life problems. The approaches differ somewhat in their theoretical goals and methodology (see Buchner, 1995 for a more detailed comparison). The tradition initiated by Broadbent emphasizes the distinction between cognitive problem-solving processes that operate under awareness versus outside of awareness, and typically employs mathematically well-defined computerized systems. The tradition initiated by Dörner, on the other hand, is interested in the interplay of cognitive, motivational, and social components of problem solving, play of contain up to 2,000 highly interconnected variables (e.g., Dörner, Kreuzig, Reither, \& Stäudel's, 1983, LOHHAUSEN project).

With the aforementioned considerations in mind, it is not surprising that there exists a wide variety of definitions of the term CPS that have relatively little in common (e.g. Frensch \& Funke, 1995b). Any general conclusion regarding CPS, however, and any theoretical model of CPS can only be 
meaningful if all agree on what constitutes a problem and what constitutes CPS. For the remainder of this chapter we define CPS as follows:

Complex problem solving occurs to overcome barriers between a given state and a desired goal state by means of behavioral and/or cognitive, multi-step activities. The given state, goal state, and barriers between given state and goal state are complex, change dynamically during problem solving, and are intransparent. The exact properties of the given state, goal state, and barriers are unknown to the solver at the outset. CPS implies the efficient interaction between a solver and the situational requirements of the task, and involves a solver's cognitive, emotional, personal, and social abilities and knowledge. (Frensch \& Funke, 1995b, p.18)

\section{INTELLIGENCE AND COMPLEX PROBLEM SOLVING}

In this section, we review some of the research on the relation between CPS and intelligence that has mainly been conducted in the past 15 years. In the relevant studies, intelligence was assessed by traditional intelligence tests or specific subtests. The assumption underlying this research is that a person's IQ score reflects some global and relatively stable intellectual ability that might be associated with CPS. In our review, we distinguish CPS that is de pendent on the intended actions of a problem solver (i.e., explicit problem solving) and problem solving that occurs, more or less, outside the realm of intention (i.e., implicit problem solving). For both types of CPS, we ask to what extent individual differences in CPS competence might be tied to individual differences in intelligence (for a more extensive discussion of this issue, see Wenke \& Frensch, 2003).

\section{Explicit Complex Problem Solving}

With few exceptions, the tasks used to assess complex explicit problem solving competence consist of dynamic scenarios presented on a computer, with the number of (independent exogenous and interconnected endogenous) variables ranging from 3 to about 2,000. The scenarios are described to research participants with the more or less clearly specified goal to optimize some aspects of the scenario's output (for a review, see Funke, 1995, 2006).

Perhaps surprisingly, empirical support for a relation between intelligence and problem solving ability is poor. Typically, the reported correlations are low or even zero, at least when the problem situation is intransparent or the goal to be achieved is poorly specified (for detailed reviews, see Kluwe, Misiak, \& Haider, 1991, as well as Beckmann \& Guthke 1995). The probably best-known study producing zero correlations was conducted by Dörner and colleagues (1983) in the early 1980s using the
LOHHAUSEN system. Participants' task was to "take care of the future prosperity" of a small town called LOHHAUSEN over a simulated 10-year proser period. About 2,000 variables were involved in this system (e.g., number of inhabitants, earnings of the industry, etc.). Participants interacted with the system through an experimenter. Problem-solving competence on this task did not correlate with the Raven's Advanced Progressive Matrices (APM; the Culture Fair Intelligence Test (Cattell \& Weiss, 1980).

Results such as these have been interpreted and discussed quite controversially by different groups of researchers. One group of researchers (e.g., Dörner \& Kreuzig, 1983; Putz-Osterloh, 1981) has argued that zero correlations between problem-solving competence and general intelligence refocologically less valid flect the fact that traditional IQ measures the researchers claim that in $\mathrm{dy}$ than CPS measures. More specifically, these researchers claim that in dy-
namic scenarios (a) the goals are often ill specified, (b) information needs to be actively sought after, and (c) semantic and contextual embeddedness (i.e., a meaningful cover story) is almost always present, and that traditional (i.e., a meaning intellectual abilities (such as the intelligence tests do not measure the intellectual abilities (such as the so-called operative intelligence; Dörner, 1986) required for successfu problem-solving performance in highly complex and ecologically valid environments.

According to a second group of researchers (e.g., Funke, 1983, 1984; Kluwe et al., 1991), low correlations between IQ and CPS are due to methodological and conceptual shortcomings. Kluwe et al. (1991) have pointed out, for instance, that it is impossible to derive valid indicators of probout, for instance, that it is impossible to derive valid indicators of problem-solving performance for tasks that are not formally tractable and thu do not possess a mathematically optimal solution. Indeed, when different dependent measures are used in studies with the same scenario (i.e. TAILORSHOP; e.g., Funke, 1983; Putz-Osterloh, 1981; Süß, Kersting, \& Oberauer, 1991, 1993), then the empirical findings frequently differ for different dependent variables.

Second, the reliability of the performance indexes is often low (e.g., Funke, 1983, 1984; Kluwe et al., 1991), ranging between .2 to .7, depending Fn the dependent variable used (see, e.g., Müller, 1993; Putz-Osterloh \& Haupts, 1989; Strohschneider, 1986). Other quite serious methodological criticisms concern the narrow sampling of IQ in most of the studies mentioned earlier (e.g., Funke, 1991), and the different ecological validity of the scenarios.

However, the empirical picture is far more complicated and less clear than might have been suggested thus far. Although zero correlations between test intelligence and complex problem-solving competence are frequently obtained, this is not always the case. For example, Putz-Osterloh (1981; Putz-Osterloh \& Lüer, 1981) has argued that the relation between 
global intelligence and complex problem-solving competence is mediated by the transparency of the problem-solving task. Like Dörner et al. (1983), Putz-Osterloh (1981) failed to find significant correlations between problem-solving competence and the APM in an intransparent experimental condition with the TAILORSHOP scenario, a scenario simulating a small company in which shirt production and sales are controlled via purchasing raw materials and modifying the production capacity in terms of the number of workers and machines. Participants' goal in the study was to maximize the company's profit, either in a transparent condition, in which they had access to a diagram depicting the relations between the system variables, or in an intransparent condition in which no diagram was shown.

Putz-Osterloh (1981, see also Putz-Osterloh \& Lüer, 1981; Hörmann \& Thomas, 1989) found a statistically reliable relation $($ Tau $=.22)$ between IQ and problem-solving competence (operationalized by the number of months with increasing capital assets) in the transparent experimental condition (but see Funke, 1983, for different results).

A different moderator variable affecting the link between global intelligence and complex problem-solving competence has been suggested by Strohschneider (1991). The author, using the MORO system in which participants are asked to improve the living conditions of nomads in the Sahel zone, manipulated the specificity of the to-be-attained goals (cf. Burns \& Vollmeyer, 2002). In the specific-goal condition, participants were asked to reach specified values on critical variables (e.g., number of cattle, number of inhabitants, etc.). In the unspecific-goal condition, the participants' task was to take actions that guaranteed long-term improvements of the MORO living conditions.

In the unspecific-goal condition, problem-solving performance did not correlate with general intelligence as measured by the Berlin Intelligence Structure test (BIS, Jäger, 1982; Jäger, Süß, \& Beauducel, 1997); however, substantial correlations (up to $r=-.59$ ) were found in the specific-goal condition.

Yet another variable affecting the relation between global intelligence and complex problem-solving ability may be the semantic context of a problem-solving task. Hesse (1982) investigated the impact of the semantic embeddedness of the problem-solving task on the relation between IQ and CPS. In the semantic condition, participants were asked to solve the DORI problem, a computerized system involving ecological variables and relations. In the semantic-free condition, a system with an isomorphic problem structure but without the cover story and without meaningful variable names was presented to the participants. In addition, transparency was manipulated in the same way as had been done in the Putz-Osterloh (1981) experiment described earlier. Hesse (1982) obtained moderate correlations between problem-solving performance and APM scores only in the seman- tic-free condition $(r=.38$ and $r=.46$ for the transparent and the intransparent condition, respectively).

On the whole, the empirical findings described earlier do not support a strong link between global intelligence and complex problem-solving competence when goal specificity and transparency are low and when the semantic content is rich; the link appears to be somewhat stronger when the intelligence-testing conditions more closely resemble the problem-solving testing conditions. We agree with Kluwe et al. (1991) that, on the basis of these results, it cannot be determined whether low correlations are due to invalid intelligence testing (i.e., their failure to assess real-world intellectual abilities necessary for dealing with complexity), or are due to a lack of reliability of the CPS measures. The heterogeneity of the scenarios and IQ tests used further complicates the interpretation of the existing results.

In the research reviewed next, IQ subtests such as the ones that are inherent in the BIS or learning-test scores were correlated with CPS performance. For example, Süß et al. (1991, 1993; see also Hussy, 1991) had problem solvers work on an intransparent version of the TAILORSHOP. The authors hypothesized that to successfully control this system, problem solvers need to infer the relations among critical variables and need to de duce meaningful goals and actions. Therefore, reasoning ability, as assessed by the BIS-factor $\mathrm{K}$ (processing capacity, capturing the ability to recognize relations and rules and to form logical inferences in figure series, number series, and verbal analogies), was assumed to be the single best predictor of problem-solving ability. This is indeed what the authors found Overall problem-solving performance correlated substantially with $\mathrm{K}(r=$ .47). In addition, knowledge (specific system knowledge as well as general economic knowledge) was found to be a predictor of problem solving as well (see also Putz-Osterloh, 1993).

Similar findings have been reported by Hörmann and Thomas (1989) who administered the TAILORSHOP under two different transparency conditions. When problem solvers' system knowledge, as assessed by a questionnaire, was high, then the K-factor (indicating capacity, $r=.72$ ) and the $\mathrm{G}$-factor (indicating memory performance, $r=.54$ ) correlated with CPS performance in the intransparent condition, whereas the B-factor (indicating processing speed, $r=.77$ ) was the best predictor in the transparent condition. However, when system knowledge was not considered, then significant correlations only emerged in the transparent condition.

A different "componential" approach has been taken by Beckmann (1994; for a comprehensive overview, see Beckmann \& Guthke, 1995). Beckmann and colleagues argued that successful problem-solving performance involves the ability to learn from success and failure. The authors therefore used learning tests (e.g., Guthke \& Beckmann, 2003) that assess problem solvers learning potential, in addition to the reasoning subtests of traditional intelli- 
gence tests (Intelligence Structure Test; Amthauer, Brocke, Liepmann, \& Beauducel, 2001, and Learning Test Battery "Reasoning," LTS 3; Guthke, Jäger, \& Schmidt, 1983) to predict problem-solving performance and knowledge acquisition. Diagrams for which the relevant relations need to be filled in are used to assess the latter. The authors' six-variable system is based on a linear equation system, and was administered in either an abstract MACHINE version or in a semantically meaningful version (CHERRYTREE, for which water supply, warmth, etc., had to be manipulated to control the growth of cherries, leaves, and beetles).

In the abstract MACHINE version, problem solvers acquired substantial system knowledge, and learning-test scores correlated substantially with the system knowledge measure as well as with problem-solving performance measures, whereas traditional intelligence subtest scores only correlated (albeit to a smaller degree) with problem-solving performance. In contrast, in the CHERRYTREE version, problem solvers did not demonstrate system knowledge and test scores did not (regardless of type) correlate with problem-solving performance. Interestingly, the two experimental groups (i.e., MACHINE vs. CHERRYTREE) did not differ in terms of the quality of their CPS performance, that is, in their control of the system. This and similar results have led several researchers (e.g., Berry \& Broadbent, 1984) to propose different modes of learning and of problem solving; we return to this issue in the next section when we discuss implicit problem solving.

To summarize, when specific intelligence components are correlated with problem-solving performance in complex systems and when the problem solving goals are clearly specified, then moderate to substantial correlations are obtained, even under intransparent task conditions. The most important intelligence components predicting problem-solving competence appear to be processing capacity-reasoning ability and learning potential. Semantic content appears to be an important mediator of the relation between abilities and CPS, implying that the content may activate prior knowledge and affect the problem representation. Furthermore, inconsistent results have been obtained regarding the relation between system knowledge (i.e., knowledge about the relations among variables) and problem-solving performance.

\section{Implicit Complex Problem Solving}

Some recent findings with artificial grammar learning, sequence learning, and CPS tasks all suggest that people are capable of successfully solving problems even when they are not able to verbally express the knowledge they are utilizing (e.g., Frensch \& Rünger, 2003). Such findings have led some researchers (e.g., Berry \& Broadbent, 1984, 1987; Nissen \&.
Bullemer, 1987; Reber, 1967, 1969) to propose independent learning systems that might underlie performance in a problem-solving task, an explicit learning system and an implicit learning system. The former is thought to be based on deliberate hypothesis testing, to be selective with respect to what is learned, and to lead to consciously accessible and verbalizable knowledge. Implicit learning, on the other hand, has been characterized as involving "the unselective and passive aggregation of information about the co-occurrence of environmental events and features" (Hayes \& Broadbent, 1988, p. 251). Thus, implicit learning is assumed to take place irrespective of the intention to learn, to not rely on hypothesis testing, and to lead to implicit (tacit) knowledge that cannot or can only partially be accessed (Frensch, 1998). Furthermore, it has been argued (Reber, Walkenfield, \& Hernstadt, 1991; see also Anderson, 1998) that implicit learning is an evolutionary older, less variable, and more robust ability, suggesting that problem-solving performance that is based on implicit learning might not be correlated with intelligence.

Reber et al. (1991) were among the first to empirically explore the relation between implicit learning and intelligence. The authors compared participants' performance on an "explicit" letter series completion task (i.e., requiring an explicit search for underlying rules) with implicit learning (i.e., a well-formedness judgment) following an artificial grammar learning task. Reber et al. were able to show that series completion, but not implicit learning, was associated with global intelligence. During the learning phase of the artificial grammar learning task, participants were instructed to memorize letter strings produced by a finite state grammar. They were informed about the existence of rules underlying the strings only after the learning phase had ended, that is, before the test phase took place. During the test phase, participants were asked to judge whether a given string corresponded to the rules (i.e., well-formedness task). To ensure a common metric for the series completion task and the well-formedness task, performance on the series completion task was assessed via two-choice response alternatives. In addition, participants were required to explain their choices.

Reber et al. (1991) found relatively small individual differences on the well-formedness task as compared to much larger individual differences on the series completion task. This result could be corroborated by a re-analysis of former studies (e.g., Reber, 1976) in which implicit versus explicit learning was manipulated by varying the instruction for the artificial grammar task.

More to the point and much more interesting was the fact that Reber et al. (1991) could show that participants' Wechsler Adult Intelligence Scale scores $(M=110, S D=21.2)$ correlated only weakly and nonsignificantly with performance on the well-formedness task $(r=.25)$. The inter- 
correlation between the two tasks did not reach significance $(r=.32)$. Thus, implicit learning did not correlate significantly with IQ.

Recently, McGeorge, Crawford, and Kelly (1997) replicated and extended the earlier findings from Reber et al. (1991) in interesting ways. First, a factor analysis showed that although the correlation between performance on the implicit task and overall IQ was not significant $(r=.12)$, there was a small but statistically reliable correlation between implicit learning and the Perceptual Organization factor $(r=.19)$. Interestingly, this factor is the one most clearly associated with fluid intelligence. Second, there were no differences in performance on the implicit task with increasing age.

Furthermore, Maybery, Taylor, and O'Brien-Malone (1995) found that performance on an implicit contingency detection task was not related to IQ $(r=.02$ and .04 for children in Grades $1-2$ and 6-7, respectively). Also, the children in these studies showed no association between their success on the implicit task and actual verbalized knowledge of the contingency tested $(r=.05$ for both groups). Interestingly, the low correlations between implicit learning and IQ seem not to have been due to lack of variation in implicit functioning. That is, there were individual differences in implicit learning but these were not related to the differences obtained on the IQ measure. Also of interest is the fact that performance on the implicit tasks increased systematically with age.

Unfortunately, in more recent work, Fletcher, Maybery, and Bennett (2000) were not able to replicate their earlier findings. Comparing 20 children with intellectual disability (mean mental age $=$ approximately 5.8 years) with intellectually gifted children (mean mental age $=$ approximately 12.4 years) of similar chronological age (approximately 9.5 years), the authors found that implicit learning varied with intellectual level. It is unclear why the earlier and the more recent findings using essentially the same methodology yielded conflicting results.

In a somewhat different and yet related area of research, Ellis and colleagues have found that individuals identified as retarded often display intact incidental learning. In the first of their studies, Ellis, Katz, and Williams (1987) found that mildly retarded adolescents, normal children, and normal adults were all equivalent in incidental learning of location. As with the studies discussed earlier, individual differences were obtained but were unrelated to gross measures of high-level cognitive functioning.

Ellis and Allison (1988) painted a more complex picture. Incidental learning of frequency of occurrence was equivalent for mildly retarded adolescents and college students, but only for visual information. Although many individuals with a diagnosis of retardation displayed normal incidental learning of verbal-semantic material, several such individuals did not. The findings suggest that uncontrolled, unintentional learning processes show little age and IQ variation when visual-spatial or noncomplex materi- als are used, but that individual differences might emerge in processing of verbal or complex materials. Anderson (1998) has recently reviewed research into related phenomena, arguing that variation in IQ is associated primarily with variations in mechanisms that are amenable to conscious control and reflection.

On the whole, an empirical relation between complex implicit problem solving and intelligence is usually not obtained. The typically obtained null findings are nevertheless interesting because they point to the possibility that implicit and explicit problem-solving competence might rely on different intellectual abilities

\section{ISSUES FOR FUTURE RESEARCH}

In this section of the chapter we address two issues that have begun to attract the interest of researchers in the CPS community and might well guide much of the future research in the area: (a) the question of whether CPS is a construct that is independent of other cognitive abilities, and (b) the question of the domain specificity of strategies and representations.

\section{Is There an Independent Construct of CPS?}

One of the interesting questions of this research is the following: is there an independent construct of CPS or are there only "normal" problem-solving processes operating on complex environments? The question can also be posed this way: are the CPS processes of such a kind that a new quality of problem solving is reached, or do we have only an extension on the task dimension with respect to complexity but not on the level of cognitive processes?

A recent study by Wittmann and Süß (1999) addressed this question and asked for the cognitive prerequisites of CPS. In an extensive data collection, 136 students from Mannheim University worked on three microworlds over the course of 3 days. Each microworld was performed twice with changed starting values: (a) a simulation called POWERPLANT (Wallach, 1998 ), (b) the Berlin version of the famous TAILORSHOP (Süß Faulhaber, 1990), and (c) the economic microworld LEARN (Millin, 1996), which-similar to LOHHAUSEN-consists of over 2,000 variable: Additionally, all participants took the BIS-4 (Jäger, Süß, \& Beauduce, 1997) and worked on nine tasks of a test battery for working memory capacity (Oberauer \& Süß, 1996).

It turned out that for all three microworlds, the processing capacity (as measured with the BIS-4) was a substantial predictor of problem-solving quality. But just as influential was the system-specific knowledge. Both predictors explained around $30 \%$ each of the variance of the aggregated CPS 
scores. "Speed of information processing" was with $5 \%$ explained variance without importance. Also, working memory capacity explained variance above processing capacity. Wittmann and Süß (1999) as well as Süß (1999) drew the conclusion from these results that, in principle, CPS might be seen as a construct of its own right, but that at the same time, the effects could be explained by referring to intelligence and domain-specific knowledge.

Considering the study and the interpretation arrived at by the authors, the question still remains if there exists a unique capacity for solving complex problems. If there indeed exist differences between simple and CPS, then one must be able to demonstrate a distinctive feature that separates the one from the other. This has not been demonstrated yet in terms of cognitive processes, but only in terms of different task descriptions.

An empirical argument against a separate ability of CPS comes from Süß (2001, p. 127 f.). He summarized several of his own microworld studies in which he regularly assessed intelligence and knowledge. According to his analyses, most of the CPS variance could be explained by these two indicators - therefore, he argued that we do not need a construct like CPS besides intelligence and knowledge.

A different view is implied by recent PISA results (the international study on student achievements). In the German national extension of PISA, computer simulated microworlds have been used in addition to an intelligence test and other more conventional problem-solving instruments (see Klieme, Funke, Leutner, Reimann, \& Wirth, 2001). It turned out in multidimensional scaling analyses that the conventional problem solving is located close to analytical reasoning, but knowledge acquisition and system control based on parameters from a finite state automaton which served as microworld constitute a separate dimension independent of test intelligence. This result could be interpreted as supporting the assumption of an independent construct.

From our view, the question about an independent CPS construct remains open until precise process models of CPS activities are presented that differ from models for simple problems. Today, we can only be certain that CPS research introduced new tasks to the problem solver, tasks that have not been analyzed before. Whether different cognitive abilities are necessary which lead to different processes cannot be answered today.

\section{Domain Specificity of Strategies and Representations}

What determines the mental representation of a problem? The assumption that structural features of a problem (i.e., type of dependencies between variables, time horizon, requested information processing, etc.) are important has been rejected by studies with so-called "problem isomorphs." Such isomorphs are structurally equivalent versions of one and the same prob- lem in different "clothes." Early research by Kotovsky, Hayes, and Simon (1985) has shown that isomorph problems produce different types of representation and-as a consequence-also different solution strategies. Such isomorphs have been used for complex problems by Funke (1992; ALTOEL) and Beckmann (1994; KIRSCHBAUM). As was the case with simple problems, the different versions of the same complex problem produce significant differences with respect to the acquired knowledge about the problem. These results demonstrate the massive effects of context: it seems that problem solving-in the same way as other cognitive functions-is highly driven by semantic embedding and knowledge. The idea of an abstract context-independent capacity for solving problems of a certain structure is not supported by this research.

Newell, Shaw, and Simon (1959) attracted much attention with their "general problem solver" (GPS). They believed at that time that GPS could be a universal procedure which, independent of domains, would solve every problem. Nowadays, we see the restrictions of the GPS more clearly, two of them being the most important:

1. GPS is not as general as one might think because it works only for the small class of well-defined problems. The urgent problems to mankind are ill-defined problems which cannot be solved by algorithms but which need ethical and moral considerations as guiding principles.

2. GPS has ignored domain-specific knowledge and domain-specific strategies, which play an important role in our daily problem-solving activities. To describe problem solving as a procedure which solves problems independient of their context was a fascinating idea but the ignorance of accumulated knowledge and its use by intelligent problem solvers turns out to be a deficit of that approach.

\section{SOME MYTHS OF RESEARCH ON THINKING \\ AND PROBLEM SOLVING}

With the advent of CPS research, we are sailing into new ports of our scientific world, but with us on board remain some of the unsolved research questions and also some of the myths of traditional research. Following, we present our list of the top 10 assumptions that currently seriously undermine progress in the area of CPS research because they are not discussed broadly and because they have the status of implicit beliefs-the reason why we call them myths:

1. Thinking and problem solving occur (solely) in the head-Isn't it true that we need our brain for problem solving? For sure, without the brain, goal-directed problem solving would never happen. But the real process 
requires an interaction with the environment (the scissors metaphor used by Herbert Simon) and it remains fair to request research about the ecology of thinking (Graumann, 2002), which is present in the recent approach of ecological rationality (see Gigerenzer \& Selten, 2001).

2. The more complex the problem, the more complex the cognitive activities for problem solving - This is an assumption, which was questioned as early as 1908 by Karl Bühler. What operations will be used on the stage of problem solving is not only determined by the type of problem but also by the intended operations. For example, the unbelievable capacity of a mental calculator, who computes in his head and within a minute the 137. root of a number consisting of 1,000 places, needs no new concepts to explain this enormous performance. As Bredenkamp (1990) could demonstrate, even the reader of this chapter would be able to do that-at least in principle, if he or she is willing to train extensively on certain procedures and to have the table of logarithms available by heart. The message is this: It is a very complex task but the cognitive procedures behind the scene are very normal.

3. Thinking and problem solving are cognitive activities that have little or nothing to do with emotion - The divergence of cognition and emotion as two different areas of psychological research has been a historical fact, which we have to overcome as soon as possible. It is not true that we deal with either cognition or with emotion. A huge amount of research demonstrates the strong interaction between the two areas. Problem solving in complex domains has much to do with emotion regulation; emotions trigger the way problems are tackled (Fiedler, 2001; Forgas, 2001; Schwarz, 2000; Spering, Wagener, \& Funke, 2005)

4. Problem solving is a universal domain-independent ability-The assumption of a universal domain-independent ability was part of the early research program called "information processing approach." The idea of a domain-independent ability was fascinating but as empirical evidence showed that cognition is a highly domain-specific enterprise.

5. Thinking and problem solving occurs by the use of rules-It is true that a lot of problem solving and thinking can be reconstructed as a series of rules which are followed by the problem solver. In certain environments, the use of plans will be helpful and lead to the goal. But there are other situations in which the control of action is more triggered by the events and the environment than by following a fixed plan. "Situated cognition" (Clark, 1997; Hutchins, 1995) makes the point that thinking does not occur solely in the head but partly also in the word. This has been demonstrated in more detail in point 1 . The assumption of rule-based processing is standard in so-called production systems, which are used for cognitive modeling (e.g., ACT-R from Anderson \& Lebiere, 1998). On the other hand, there exist connectionist systems, which completely resist the use of symbolic representations (for a review, see Medler, 1998). It is true that modeling of problem solving by means of production rules might be the first choice, as has been done by Wallach (1998). But even complex processes of planning can be successfully conceived of as connectionistic networks (Schenck, 2001). Also, PSI theory (Dörner et al., 2002) is based completely on a connectionistic approach.

6. Simple problem solving can be anaiyzed experimentally, complex problem solving not because of its system character-Complex systems have a lot of connections within and between the different subsystems. On the first view, a systematic testing of the different functions and their interactions seems to not be possible. But nevertheless, the highly skilled art of system analysis allows it, even with complex systems to localize and diagnose disturbances as well as latent functions.

7. One needs many participants to identify the small effects, which are important for thinking and reasoning-Indeed it is necessary to have many observations if the expected effect size is small. On the other side, if one has a strong theory, even a single participant would be enough to falsify a universal hypothesis. For research on thinking and problem solving, this fact implies the following: Single cases cannot only be used for the generation of hypothesis (Kluwe, 1995) but under given conditions they can also be used for hypothesis testing.

8. Problem solving and thinking (especially complex problem solving) could not be learned-Especially in the context of complex requirements, the pedagogics of CPS seem not to work well. You cannot easily teach "critical thinking" (Dauer, 1989; Halpern, 1989). But with computer-simulated microworlds, one can use fast motion and slow motion to allow for a precise observation of consequences. As Dörner (1989, p. 305) argued, the use of different time scales allows for multiple learning by means of "symphony of requirements." This argument goes as follows: if you make many experiences on different time scales with different scenarios, you will learn a lot about actions and their consequences. To play is always a good preparation for the real thing. With the use of computer-simulated microworlds, it never was more easy to have these experiences available.

9. The use of brain imaging allows new insights into the active brain. Therefore, traditional cognitive theories will be replaced by neurological concepts-It is true that the potential of brain imaging has been increased tremendously (Posner \& Raichle, 1994). The expectations are set to watch the brain life in action. Will we be listening to the brain if it is working on complex problems? And if it will be possible, what could be seen? Op de Beeck, Wagemans, and Vogels (2001) wrote the following in their critical review: "... if one wants to construct a cognitive model of behavior, then a mere localization of these processes is not that important (con- 
trary to its importance for neuropsychology). For a cognitive scientist, it is is important which cognitive processes are involved in a task and how these a computed, but it does not matter where they are computed ..." (p. 344).

The old discussion about the right level of analysis started by Marr (1982) in the context of his work on artificial intelligence models of seeing has to be in the context of here. Also, the controversial debate around connectionistic reme that issue (see Broadbent, 1985; McClelland, 1988; McClelland \& Rumelhart, 1985; McCloskey, 1991). Do new insights about neural structures really shed new light on theories which are formulated on a much more abstract level of analysis? The answer is also, in the case of brain imaging techniques, similar as in the debates about connectionistic systems: It is an interesting issue how the brain realizes cerconnection are on a more abstract tain activities but the finally important questions are on a more abstract "new phrenology" (Uttal, 2001) will hopefully sleep in his box.

10. CPS is an intercultural stable component of human cognition-This last point relates to the cultural boundedness of cognitive processes in general and of problem solving in special (see Nisbett 2003; Nisbett \& Norenzayan, 2002). Especially in the context of CPS, a lot of interesting results from cross-cultural studies are available today (Strohschneider, 1996, 2001 Strohschneider \& Güss, 1998, 1999). Culturally bound problem-solving styles are the expression of cultural boundedness of thinking and problem solving, which we should accept more intensively in the interest of our own survival.

\section{SUMMARY AND CONCLUSIONS}

The study of CPS by means of computer-simulated scenarios is indeed a huge extension of traditional research on thinking and problem solving. The results from the last decade provide a deeper understanding of the behavior of human actors in complex situations. But even today we have no final answers to key questions like trainability. The fundamental idea simulate reality and to watch actors in their problem-solving acidea-to simulate reality and to watch actors in the part of basic idea at the beginning of the 20th century when German working psychologists used the idea of work specimens as diagnostic approach, which they called "Psychotechnik." It is time for us to keep this idea running in the 21 st century.

The first goal of this chapter was to discuss to what extent, if indeed at all, individual differences in complex problem-solving competence are related to individual differences in intelligence. Two forms of problem solving were distinguished: explicit problem solving, that is, problem solving that is controlled by a problem solver's intentions; and implicit problem solving, that is, automatic or nonconscious CPS

Our main conclusions are as follows. First, there exists no convincing empirical evidence that would support a relation, let alone a causal relation, between complex explicit or implicit problem-solving competence, on the one hand, and global intelligence on the other hand. It is important to emphasize that this conclusion is one that is based on a lack of evidence, not necessarily a lack of theoretical relation. That is, we do not deny the theoretical possibility that a relation between global intelligence and CPS competence might exist; we argue only that there exists no convincing empirical evidence that would support such a relation. Nevertheless, the evidence reviewed in this chapter is consistent with a wealth of empirical findings on the relation between intelligence and simple problem solving which suggests that even when a relation between intelligence and problem-solving competence is obtained, it is quite modest in size (e.g., Sternberg, 1982).

Second, however, there exists a considerable amount of empirical data suggesting that specific components of intelligence, such as processing capacity, might be related to specific components of explicit CPS. To what extent a similar conclusion might be warranted for implicit CPS remains to be seen; the available research has, thus far, not addressed this specific question.

On the whole then, the available evidence suggests that the global concepts of intelligence and problem solving are not related, but that specific subcomponents of intelligence and explicit problem solving might share variance. The existing empirical evidence does not speak, unfortunately, to the issue of whether subcomponents of intelligence predict subcomponents of problem solving or whether the opposite causal relation holds; the empirical designs used up to now simply cannot answer this question.

\section{REFERENCES}

Amthauer, R., Brocke, B., Liepmann, D., \& Beauducel, A. (2001). Intelligenz-Struktur-Test $2000 R$ [Assessment of Intelligence Structure]. Göttingen Germany: Hogrefe.

Anderson, J. R., Boyle, C. B., \& Reiser, B. J. (1985). Intelligent tutoring systems. Science, $228,456-462$.

Anderson, J. R., \& Lebiere, C. (Eds.). (1998). The atomic components of thought. Mahwah, NJ: Lawrence Erlbaum Associates.

Anderson, M. (1998). Individual differences in intelligence. In K. Kirsner, C. Speelman, M. Maybery, A. O’Brien-Malone, M. Anderson, \& C. MacLeod (Eds.) Implicit and explicit processes (pp. 171-185). Mahwah, NJ: Lawrence Erlbaum Associates.

Anzai, K., \& Simon, H. A. (1979). The theory of learning by doing. Psychological Review, 86, 124-140. 
Beckmann, J. F. (1994). Lernen und komplexes Problemlösen. Ein Beitrag zur Konstruktvalidierung von Lerntests [Learning and problem solving. A contribution to validate learning potential tests]. Bonn, Germany: Holos.

Beckmann, J. F., \& Guthke, J. (1995). Complex problem solving, intelligence, and learning ability. In P. A. Frensch \& J. Funke (Eds.), Complex problem solving. The European perspective (pp. 3-25). Hillsdale, NJ: Lawrence Erlbaum Associates.

Berry, D. C., \& Broadbent, D. E. (1984). On the relationship between task performance and associated verbalizable knowledge. Quarterly Journal of Experimental Psychology, 36A, 209-231.

Berry, D. C., \& Broadbent, D. E. (1987). The combination of explicit and implicit learning processes in task control. Psychological Research, 49, 7-15.

Berry, D. C., \& Broadbent, D. E. (1995). Implicit learning in the control of complex systems. In P. A. Frensch \& J. Funke (Eds.), Complex problem solving. The European perspective (pp. 3-25). Hillsdale, NJ: Lawrence Erlbaum Associates.

Bhaskar, R., \& Simon, H. A. (1977). Problem solving in semantically rich domains: An example from engineering thermodynamics. Cognitive Science, 1 , $193-215$

Bredenkamp, J. (1990). Kognitionspsychologische Untersuchungen eines Rechenkünstlers [Cognitive studies of a mathematical genius]. In H. Feger (Ed.), Wissenschaft und Verantwortung. Festschrift für Karl Josef Klauer (pp. 47-70). Göttingen, Germany: Hogrefe.

Broadbent, D. E. (1977). Levels, hierarchies, and the locus of control. Quarterby Journal of Experimental Psychology, 29, 181-201.

Broadbent, D. E. (1985). A question of levels: Comments on McClelland and Rumelhart. Joumal of Experimental Psychology: General, 114, 189-192.

Buchner, A. (1995). Basic topics and approaches to the study of complex problem solving. In P. A. Frensch \& J. Funke (Eds.), Complex problem solving. The European perspective (pp. 27-63). Hillsdale, NJ: Lawrence Erlbaum Associates.

Bühler, K. (1908). Antwort auf die von W.Wundt erhobenen Einwände gegen die Methode der Selbstbeobachtung an experimentell erzeugten Erlebnissen [Response to W. Wundt's objections to the method of self-observation of experimentally generated experiences]. Archiv für die Gesamte Psychologie, 12, 93-112.

Burns, B. D., \& Vollmeyer, R. (2002). Goal specificity effects on hypothesis testing in problem solving. Quarterly Journal of Experimental Psychology, 55A, 241-261.

Cattell, R. B., \& Weiss, R. H. (1980). Culture Fair Intelligence Test, Scale 3 (CFT3). Göttingen, Germany: Hogrefe.

Chase, W. G., \& Simon, H. A. (1973). Perception in chess. Cognitive Psychology, 4, 55-81.

Chi, M. T. H., Feltovich, P. J., \& Glaser, R. (1981). Categorization and representation of physics problems by experts and novices. Cognitive Science, 5, 121-152.

Clark, A. (1997). Being there. Putting brain, body, and world together again. Cambridge, MA: MIT Press.

Dauer, F. W. (1989). Critical thinking. An introduction to reasoning. New York: Oxford University Press.

Dörner, D. (1975). Wie Menschen eine Welt verbessern wollten [How people wanted to improve a world]. Bild der Wissenschaft, 12, 48-53.

Dörner, D. (1980). On the difficulty people have in dealing with complexity. Simulation Eं Games, 11, 87-106.

Dörner, D. (1986). Diagnostik der operativen Intelligenz [Assessment of operative intelligence]. Diagnostica, 32, 290-308.
Dörner, D. (1989). Die Logik des Mißlingens. Strategisches Denken in komplexen Situationen [The logic of failure. Recognizing and avoiding error in complex situations]. Hamburg, Germany: Rowohlt.

Dörner, D. Bartl, C., Detje, F., Gerdes, J., Halcour, D., Schaub, H., et al. (2002). Die Mechanik des Seelenwagens. Eine neuronale Theorie der Handlungsregulation [The mechanics of the soul wagon. A neuronal theory of action regulation]. Bern, Switzerland: Huber.

Dörner, D., \& Kreuzig, H. W. (1983). Problemlösefähigkeit und Intelligenz [Problem solving and intelligence]. Psychologische Rundschau, 34, 185-192.

Dörner D Kreuzig. H. W. Reither, F. \& Stäudel, T. (1983). Lohhausen. Vom Umgang mit Unbestimmtheit und Komplexität [Lohhausen. On dealing with uncertainty and complexity]. Bern, Switzerland: Huber.

Dörner, D., \& Wearing, A. (1995). Complex problem solving: Toward a (computersimulated) theory. In P. A. Frensch \& J. Funke (Eds.), Complex problem solving: The European perspective (pp. 65-99). Hillsdale, NJ: Lawrence Erlbaum Associates.

Duncker, K. (1935). Zur Psychologie des produktiven Denkens [On productive thinking]. Berlin, Germany: Springer.

Ellis, N. R., \& Allison, P. (1988). Memory for frequency of occurrence in retarded and nonretarded persons. Intelligence, $12,61-75$.

Ellis, N. R., Katz, E., \& Williams, J. E. (1987). Developmental aspects of memory for spatial location. Journal of Experimental Child Psychology, 44, 401-412.

Ewert, P. H. \& Lambert, J. F. (1932). The effect of verbal instructions upon the formation of a concept. Joumal of General Psychology, 6, 400-413.

Fiedler, K. (2001). Affective states trigger processes of assimilation and accomodation. In L. L. Martin \& G. L. Clore (Eds.), Theories of mood and cogni tion: A user's guidebook (pp. 85-98). Mahwah, NJ: Lawrence Erlbaum Associates.

Fletcher J Maybery, M. T., \& Bennett, S. (2000). Implicit learning differences: A question of developmental level? Joumal of Experimental Psychology: Learning, Memory, and Cognition, 26, 246-252.

Forgas, J. P. (2001). The Affect Infusion Model (AIM): An integrative theory of mood effects on cognition and judgment. In L. L. Martin \& G. L. Clore (Eds.), Theories of mood and cognition: $A$ user's guidebook (pp. 99-134). Mahwah, NJ: Lawrence Erlbaum Associates.

Frensch, P A (1998). One concept, multiple meanings. On how to define the concept of implicit learning. In M. A. Stadler \& P. A. Frensch (Eds.), Handbook of implicit learning (pp. 47-104). Thousand Oaks, CA: Sage.

Frensch, P. A., \& Funke, J. (Eds.). (1995a). Complex problem solving: The European perspective. Hillsdale, NJ: Lawrence Erlbaum Associates.

Frensch, P. A \& Funke, J. (1995b). Definitions, traditions, and a general framework for understanding complex problem solving. In P. A. Frensch \& J. Funke (Eds.), Complex problem solving. The European perspective (pp. 3-25). Hillsdale, NJ: Lawrence Erlbaum Associates.

Frensch, P. A., \& Rünger, D. (2003). Implicit learning. Current Directions in Psychological Science, 12, 13-17.

Funke, J. (1983). Einige Bemerkungen zu Problemen der Problemlöseforschung oder: Ist Testintelligenz doch ein Prädiktor? [Some remarks on the problems of problem solving research or: Does test intelligence predict control performance?]. Diagnostica, 29, 283-302. 
Funke, J. (1984). Diagnose der westdeutschen Problemlöseforschung in Form e. einiger Thesen [Assessment
E' Kognition, 3, 159-172.

Funke, J. (1991). Solving complex problems: Exploration and control of complex systems. In R. J. Sternberg \& P. A. Frensch (Eds.), Complex problem solving: Principles and mechanisms (pp. 185-222). Hillsdale, NJ: Lawrence Erlbaum Associates.

Funke, J. (1992). Wissen über dynamische Systeme: Erwerb, Repräsentation und Anwendung [Knowledge about dynamic systems: Acquisition, representation, and Anwendung [Knowledge about dynar
use]. Berlin, Germany: Springer.

Funke, J. (1995). Experimental research on complex problem solving. In P. A Frensch \& J. Funke (Eds.), Complex problem solving: The European perspective (pp. 243-268). Hillsdale, NJ: Lawrence Erlbaum Associates.

Funke, J. (Ed.) (1999). Themenheft komplexes problemlösen [Special issue on complex problem solving]. Psychologische Rundschau, 50(4). Funke, J. (2006). Komplexes Problemlösen [Complex problem solving]. In J. Funke (Ed.), Denken und Problemlösen (pp. 375-446). Göttingen, Germany: Hogrefe.

Gigerenzer, G., \& Selten, R. (2001). Rethinking rationality. In G. Gigerenzer \& R. Selten (Eds.), Bounded rationality. The adaptive toolbox (pp. 1-12). Cambridge, MA: MIT Press.

Graumann, C. F (2002). The phenomenological approach to people-environment studies. In R. B. Bechtel \& A. Churchman (Eds.), Handbook of environmental psychology (pp. 95-113). New York: Wiley.

Guthke, J., \& Beckmann, J. F. (2003). Dynamic assessment with diagnostic programs. In R. J. Sternberg, J. Lautrey \&. T. I. Lubart (Eds.), Models of intelligence (pp. 227-249). Washington, DC: American Psychological Association.

Guthke J., Jäger, C., \& Schmidt, I. (1983). Lerntestbatterie "Schlussfolgernde Denken" [Learning test battery "reasoning"]. Berlin: Psychodiagnostisches Zentrum.

Halpern, D. F. (1989). Thought and knowledge. An introduction to critical thinking. Hillsdale, $\mathrm{NJ}$ : Lawrence Erlbaum Associates.

Hayes, N A \& Broadbent, D. E. (1988). Two modes of learning for interactive tasks. Cognition, 28, 249-276.

Hesse, F W (1982). Effekte des semantischen Kontexts auf die Bearbeitung komplexer Probleme [Effects of semantic context on problem solving]. Zeitschrift für Experimentelle und Angewandte Psychologie, 29, 62-91.

Hörmann, J. J., \& Thomas, M. (1989). Zum zusammenhang zwischen intelligen und komplesem problemlösen [On the relationship between intelligence and complex problem solving]. Sprache E Kognition, 8, 23-31.

Hus (1991). Komplexes Problemlösen und Verarbeitungskapazität [Complex problem solving and processing capacity]. Sprache E Kognition, 10, 208-220.

Hutchins, E. (1995). Cognition in the wild. Cambridge, MA: MIT Press.

Jäger, A. O. (1982). Mehrmodale klassifikation von intelligenzleistungen [Multimodal classification of intelligent performance]. Diagnostica, 28, 195-225.

(1997). Berliner Intelligenzstrukturtest

BIS-Test, Form 4 [Berlin Intelligence Structure Test, Manual]. Göttingen, Germany: Hogrefe.

Klieme, E., Funke, J., Leutner, D., Reimann, P., \& Wirth, J. (2001). Problemlösen als fächerübergreifende kompetenz. Konzeption und erste resultate aus eine schulleistungsstudie [Problem solving as crosscurricular competence. Conceptul framework and first results from a study on school achievement]. Zeitschrift für Pädagogik, 47, 179-200
Kluwe, R. H. (1995). Single case studies and models of complex problem solving. In P. A. Frensch \& J. Funke (Eds.), Complex problem solving: The European perspective (pp. 269-291). Hillsdale, NJ: Lawrence Erlbaum Associates.

Kluwe R. H Misiak C \& Haider, H. (1991). Systems and performance in intelligence tests. In $\mathrm{H}$. Rowe (Ed.), Intelligence: Reconceptualization and measurement (pp. 227-244). Hillsdale, NJ: Lawrence Erlbaum Associates.

Kluwe, R. H., Schilde, A., Fischer, C., \& Oellerer, N. (1991). Problemlöseleistungen beim umgang mit komplexen systemen und intelligenz [Problem solving performance when interacting with complex systems and intelligence]. Diagnostica, 37, 291-313.

Kotovs , K Hayes, J. R \& Simon, H. A (1985). Why are some problems hard? Evidence from Tower of Hanoi. Cognitive Psychology, 17, 248-294.

Marr, D. (1982). Vision. A computational investigation into the human representation and processing of visual information. New York: W. H. Freeman.

Maybery, M., Taylor, M., \& O'Brien-Malone, A. (1995). Implicit learning: Sensitive to age but not IQ. Australian Joumal of Psychology, 47, 8-17.

Mayer, R. E. (1992). Thinking, problem solving, cognition (2nd ed.). New York: Freeman.

McClelland, J. L. (1988). Connectionist models and psychological evidence. Journal of Memory and Language, 27, 107-123.

McClelland, J. L., \& Rumelhart, D. E. (1985). Distributed memory and the representation of general and specific information. Joumal of Experimental Psychology: General, 114, 159-188.

McCloskey, M. (1991). Networks and theories: The place of connectionism in cognitive science. Psychological Science, 2, 387-395

McGeorge, P., Crawford, J. R., \& Kelly, S. W. (1997). The relationships between psychometric intelligence and learning in an explicit and an implicit task. Joumal of Experimental Psychology: Learning, Memory, EF Cognition, 23, 239-245.

Medler, D. A. (1998). A brief history of connectionism. Neural Computing Surveys, 1 , 61-101.

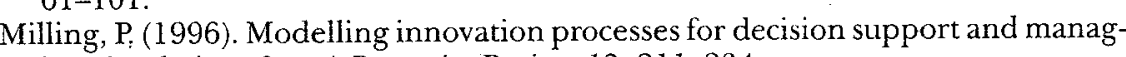
ing simulation. System Dynamics Revievu, 12, 211-234.

Müller, H. (1993). Komplexes problemlösen: Reliabilität und wissen [Complex problem solving: Reliability and knowledge]. Bonn, Germany: Holos.

Newell, A., \& Simon, H. A. (1972). Human information processing. Englewood Cliffs, NJ: Prentice Hall.

Newell, A., Shaw, J. C., \& Simon, H. A. (1959). A general problem-solving program for a computer. Computers and Automation, 8, 10-16.

Nisbett, R. E. (2003). The geography of thought. How Asians and Westerners think differently ... and why. New York: Free Press.

Nisbett, R. E., \& Norenzayan, A. (2002). Culture and cognition. In H. Pashler \& D. Medin (Eds.), Steven's handbook of experimental psychology. Third edition. Vol. 2: Memory and cognitive processes (pp. 561-597). New York: Wiley.

Nissen, M. J., \& Bullemer, P. (1987). Attentional requirements of learning: Evidence from performance measures. Cognitive Psychology, 19, 1-32.

Oberauer, K., \& Süß, H.-M. (1996). Working memory starship. Computerbasierte testbatterie zur diagnostik der arbeitsgedächtniskapazität [Computer based tes battery for the assessment of working memory]. Mannheim, Germany: Universität Mannheim, Lehrstuhl Psychologie II.

op de Beeck, H., Wagemans, J., \& Vogels, R. (2001). Can neuroimaging really tell us what the human brain is doing? The relevance of indirect measures of population activity. Acta Psychologica, 107, 323-351. 
Posner, M. I., \& Raichle, M. E. (1994). Images of mind. New York: Freeman.

Putz-Osterloh, W. (1993). Strategies for knowledge acquisition and transfer of knowledge in dynamic tasks. In G. Strube \& K.-F. Wender (Eds.), The cognitive psychology of knowledge (pp. 331-350). Amsterdam: Elsevier Science Publishers.

Putz-Osterloh, W. (1981). Über die beziehung zwischen testintelligenz und problemlöseerfolg [On the relationship between test intelligence and success in problem solving]. Zeitschrift für Psychologie, 189, 79-100.

Putz-Osterloh, W., \& Haupts, I. (1989). Zur reliabilität und Validität computergestützter diagnostik komplexer organisations- und entscheidungsstrategien [On the reliability and validity of computerbased assessment of complex organizational and decision strategies]. Untersuchungen des Psychologischen Dienstes der Bundeswehr, 24, 5-48.

Putz-Osterloh, W., \& Lüer, G. (1981). Über die Vorhersagbarkeit komplexer problemlöseleistungen durch ergebnisse in einem intelligenztest [On the predictability of complex problem solving performance by intelligence test scores]. Zeitschrift für Experimentelle und Angewandte Psychologie, 28, 309-334.

Raven, J. C., Court, J., \& Raven, J., Jr. (1980). Advanced Progressive Matrices (APM). Weinheim, Germany: Beltz.

Reber, A. S. (1967). Implicit learning of artificial grammars. Journal of Verbal Learning and Verbal Behavior, 77, 317-327.

Reber, A. S. (1969). Transfer of syntactic structure in synthetic languages. Journal of Experimental Psychology, 81, $115-119$

Reber, A. S. (1976). Implicit learning and tacit knowledge. Joumal of Experimental Psychology: Human Learning and Memory, 2, 88-94.

Reber, A. S., Walkenfield, F. F., \& Hernstadt, R. (1991). Implicit and explicit learning: Individual differences and IQ. Journal of Experimental Psychology. Learning, Memory, and Cognition, 17, 888-896.

Schenck, W. (2001). A connectionist approach to human planning. Retrieved March 11, 2005, from http://www.ub.uni-heidelberg.de/archiv/1428

Schwarz, N. (2000). Emotion, cognition, and decision making. Cognition and Emotion, 14, 433-440.

Spering, M., Wagener, D., \& Funke, J. (2005). The role of emotions in complex problem-solving. Cognition and Emotion, 19, 1252-1261.

Sternberg, R. J. (1982). Reasoning, problem solving, and intelligence. In R. J. Sternberg (Ed.), Handbook of human intelligence (pp. 225-307). Cambridge, MA: Cambridge University Press.

Sternberg, R. J. (1995). Expertise in complex problem solving: A comparison of alternative conceptions. In P. A. Frensch \& J. Funke (Eds.), Complex problem solving: The European perspective (pp. 295-321). Hillsdale, NJ: Lawrence Erlbaum Associates.

Sternberg, R. J., \& Frensch, P. A. (Eds.). (1991). Complex problem solving: Principles and mechanisms. Hillsdale, NJ: Lawrence Erlbaum Associates.

Strohschneider, S. (1986). Zur Stabilität und Validität von Handeln in komplexen Realitätsbereichen [On the stability and validity of complex problem-solving behavior]. Sprache Eீ Kognition, 5, 42-48.

Strohschneider, S. (1991). Problemlösen und Intelligenz: Über die Effekte der Konkretisierung komplexer Probleme [Complex problem solving and intelligence: On the effects of problem concreteness]. Diagnostica, 37, 353-371.
Strohschneider, S. (Ed.). (1996). Denken in Deutschland: Vergleichende Untersuchungen in Ost und West [Thinking in Germany: A comparison between East and West Germany]. Bern, Switzerland: Huber.

Strohschneider, S. (2001). Kultur - Denken - Strategie. Eine Indische Suite [Culture thinking - strategy. An Indian suite]. Bern, Switzerland: Huber.

Strohschneider, S., \& Güss, D. (1998). Planning and problem solving: Differences between Brazilian and German students. Journal of Cross-Cultural Psychology, 29, $695-716$.

Strohschneider, S., \& Güss, D. (1999). The fate of the Moros: A cross-cultural exploration of strategies in complex and dynamic decision making. International Journal of Psychology, 34, 235-252.

Süß, H.-M. (1999). Intelligenz und komplexes Problemlösen - Perspektiven für eine Kooperation zwischen differentiell-psychometrischer und kognitionspsychologischer Forschung [Intelligence and complex problem-solving. Perspectives for a cooperation between differential-psychometric and cognition-psychological research]. Psychologische Rundschau, 50, 220-228.

Süß, H.-M. (2001). Prädikative Validität der Intelligenz im schulischen und außerschulischen Bereich [Predictive validity of test intelligence for school and non-school purposes]. In E. Stern \& J. Guthke (Eds.), Perspektiven der Intelligenzforschung. Ein Lehrbuch für Fortgeschrittene (pp. 89-108). Lengerich, Germany: Pabst Science Publishers.

Süß, H.M., \& Faulhaber, J. (1990). Berliner Version der Schneiderwerkstatt. PC Simulationsprogramm [Berlin version of Tailorshop]. Berlin, Germany: Freie Universität Berlin, Fachbereich Erziehungs- und Unterrichtswissenschaften, Institut für Psychologie.

Süß, H. M., Kersting, M., \& Oberauer, K. (1991). Intelligenz und Wissen als Prädiktoren für Leistungen bei computersimulierten komplexen Problemen [Intelligence and knowledge as predictors of performance in solving complex computer-simulated problems]. Diagnostica, 37, 334-352.

Süß, H.-M., Kersting, M., \& Oberauer, K. (1993). Zur Vorhersage von Steuerungsleistungen an computersimulierten Systemen durch Wissen und Intelligenz [Predicting control performance in computersimulated systems by means of knowledge and intelligence]. Zeitschrift für Differentielle und Diagnostische Psychologie, 14, 189-203.

Uttal, W. R. (2001). The new phrenology. Cambridge, MA: MIT Press.

Wallach, D. (1998). Komplexe Regelungsprozesse. Eine kognitionswissenschaftiche Analyse [Complex control processes. A cognitive science analysis]. Wiesbaden, Germany: Deutscher Universitäts-Verlag.

Wenke, D., \& Frensch, P. A. (2003). Is success or failure at solving complex problems related to intellectual ability? In J. E. Davidson \& R. J. Sternberg (Eds.), The psychology of problem solving (pp. 87-126). Cambridge: Cambridge University Press.

Wittmann, W. W., \& Süß, H.-M. (1999). Investigating the paths between working memory, intelligence, knowledge and complex problem solving: Performances via Brunswik-symmetry. In P. L. Ackerman, P. C. Kyllonen, \& R. D. Roberts (Eds.), Learning and individual differences: Process, trait, and content (pp. 77-108). Washington, DC: American Psychological Association. 


\title{
Learning to Solve Complex Scientific Problems
}

\author{
Edited by \\ David H. Jonassen \\ University of Missouri \\ 2007
}

EA Lawrence Erlbaum Associates 